www.jmscr.igmpublication.org

Index Copernicus Value: 79.54

ISSN (e)-2347-176x ISSN (p) 2455-0450

crossref DOI: https://dx.doi.org/10.18535/jmscr/v7i6.69

\title{
Diagnostic Yield of Non Contrast Computed Tomography in evaluation of Hematuria in young adults: A prospective study
}

\author{
Authors \\ Manik Mahajan ${ }^{1 *}$, Poonam Sharma ${ }^{2}$, Rahul Gupta ${ }^{3}$ \\ ${ }^{1}$ Lecturer, Department of Radio-Diagnosis \& Imaging, Government Medical College, Jammu \\ ${ }^{2}$ Consultant Pathologist, Atulaya Healthcare, Jammu \\ ${ }^{3}$ Assistant Professor, Department of Urology, Government Medical College, Jammu \\ *Corresponding Author \\ Manik Mahajan
}

House no 109, Sector-7, Channi Himmat, Jammu (J\&K), India- 180015

\begin{abstract}
Aim: To evaluate the diagnostic yield of the role of Non Contrast Computed Tomography (NCCT) in evaluation of hematuria in young adults

Material and Methods: All the young adults (40 years or less in age) who presented with macroscopic or microscopic hematuria and were advised computed Tomography were included in the study. Detailed history and findings of clinical examination were recorded. NCCT scans were performed and findings were recorded in detail and tabulated. CECT scans and urographic scans were performed wherever indicated.

Results: Mean age of patients in the study was 29 years with male to female ratio of 2.7:1. Of all the examined cases, clinically significant cause of hematuria was seen in 43 patients (48.9\%). The most common clinically significant findings were renal or ureteric calculi seen in 32 patients (74.4\%); three cases of malignancy were also seen. Thirty seven (86.0\%) of 43 clinically significant causes were evident on non contrast images. Tiny vesical mass, urinary tract infections, PUJ obstruction, ureteric stricture, double collecting system and parapelvic cysts were detected only on contrast enhanced scans and were not apparent on non contrast images.

Conclusions: Clinically significant cause of hematuria was seen in $48.9 \%$ of Contrast enhanced CT of the young adults. Non contrast images alone were diagnostic in majority of these cases thereby reducing the requirement of additional CT examination and hence radiation exposure in radiosensitive individuals.
\end{abstract}

\section{Introduction}

Hematuria is common urological condition in young adults with reported incidence of $0.3-$ $38.7 \%$ of adults in various studies ${ }^{[1-2]}$. It can originate from any site in the urinary tract and is a common sign of urinary tract pathology.
Hematuria may be gross or microscopic. Gross hematuria is alarming and has a high predictive value for malignancy, often leading to referral to a urologist. Definition of Microscopic hematuria is controversial and several factors contribute to its definition including the urine collection method, 
hematuria detection method, number of positive results, and patient characteristics ${ }^{[3]}$. Asymptomatic microscopic hematuria is mostly a benign incidental finding ${ }^{[4-6]}$ and no specific appropriate strategy for imaging in young adults with microscopic hematuria has been developed.

Evaluation of a patient with hematuria includes proper history and physical examination. Complete evaluation includes cytology, cystoscopy, and upper tract imaging ${ }^{[3]}$. Imaging of the upper tract is required because lesions in the kidneys or ureters may be the source of blood in the urine ${ }^{[3]}$. Many imaging modalities are available with ultrasonography (USG), intravenous urography (IVU) and Computed Tomography (CT) urography being the commonest ones. USG is safe, non-invasive and quite informative in the evaluation of the kidneys and urinary bladder kidneys. However it has poor ability to detect calculi with a sensitivity of $24 \%$ and a specificity of $90 \%{ }^{[7]}$. IVU allows detection of calculi, renal parenchymal masses and lesions of the urinary collecting system and bladder and has ability to assess renal function and degree of obstruction. However, IVU could not be used to distinguish cystic from solid renal masses, had a poor sensitivity in the detection of small masses and has difficulty visualizing radiolucent stones and differentiating them from tumors, and dependence on renal function for adequate opacification of the renal parenchyma and collecting system $^{[3]}$. In contrast CT scan, especially CT urography provides single comprehensive non invasive evaluation of the urinary tract and is the current modality of choice for evaluation of painless gross or microscopic hematuria. However, CT urography requires injection of iodinated contrast material and utilizes ionizing radiation.

We therefore examined the diagnostic yield of NCCT in evaluation of young adults with hematuria and to determine whether the increased radiation dose in Contrast enhanced and urographic images are required or not

\section{Material and Methods}

This prospective study was performed in tertiary care centre in north India over a period of one year. Patients 40 years or younger who presented with gross or microscopic hematuria and referred for CT examination were included in the study. A total of $88 \mathrm{CT}$ urographic examinations were performed in patients 40 years or younger. CT was performed with 64 slice-MDCT scanner (Somatom Definition AS+ scanner from Siemens Healthcare). Renal function tests were evaluated in all the patients who underwent Contrast scans and study performed with at least 6 hours of complete fasting. No bowel preparation was required. Before the study, patients were asked to drink approx. $1000 \mathrm{ml}$ of water before the examination and wait for filling of the urinary bladder. No supplementation with saline or injection of furosemide was given. Multiplanar 2D and $3 \mathrm{D}$ reformatted images were generated on workstations from axial source images. Additional volume rendering projections of the excretory phase were also obtained wherever required. Images were reviewed by two radiologists with significant experience. Findings of the examinations were recorded in all the cases and clinically significant source of hematuria was determined. Clinically significant source was defined as per criteria specified by American Urologic Association Best Practice Policy Guidelines ${ }^{[6,8]}$. Records pertaining to additional investigations were also evaluated and findings were recorded.

\section{Results}

Eighty Eight patients with hematuria formed the material of the study. Majority of the patients were seen in $3^{\text {rd }}$ decade of life. Most of the patients were males with male to female ratio of 2.7:1.

Out of 88 patients; abnormal findings were seen in 65 patients $(73.9 \%)$ and clinically significant source of hematuria was seen in $48.9 \%$ patients (Table 1). Three life-threatening findings were observed. These included single case of renal 
mass \& two cases of vesical mass. Of these, single case of vesical mass was not evident on unenhanced images and was picked up only on contrast enhanced images. Significant source of hematuria requiring treatment was seen in 37 patients. Most of these findings were renal and/or ureteral calculi ( $n=34,91.2 \%)$, all of which were evident on non contrast images. Three findings $(\mathrm{n}=3,8.8 \%)$ that were significant and required treatment, were detected on contrast enhanced images only. These included two cases of renal abscess and single case of pyonephrosis with pyelitis.

Significant source of hematuria requiring observation only was seen in 3 cases including two cases of atrophic kidneys and one case of benign prostatic hyperplasia. All of them were detected on unenhanced images and did not require contrast scans.

There were 22 patients in which findings were clinically insignificant. The majority were benign renal cortical cysts $(n=17,77.3 \%)$. Sixteen $(72.7 \%)$ of the insignificant findings were detected on unenhanced images alone. Three cases of benign cortical cysts and two patients with duplicated renal collecting systems required contrast-enhanced images for diagnosis. Another case of parapelvic cyst with dense contents was also seen which was suspicious for renal neoplasm on unenhanced images and was appropriately diagnosed on contrast enhanced images only.

Table 1: Sources of Hematuria Identified $(n=65)$

\begin{tabular}{|c|c|c|}
\hline Category & $\begin{array}{c}\text { No. of } \\
\text { Patients }\end{array}$ & $\begin{array}{l}\text { Finding Evident on } \\
\text { Unenhanced images } \\
\text { only [No./Total (\%)] }\end{array}$ \\
\hline $\begin{array}{l}\text { Life Threatening } \\
\text { A) Renal Mass } \\
\text { B) Vesical Mass }\end{array}$ & $\begin{array}{l}1 \\
2 \\
\end{array}$ & $\begin{array}{c}1(100.0) \\
1(50.0) \\
\end{array}$ \\
\hline $\begin{array}{l}\text { Significant and Requiring } \\
\text { Treatment } \\
\text { A) Renal and/or ureteral } \\
\text { calculus } \\
\text { D) Renal Abscess } \\
\text { E) Pyonephrosis and or pyelitis }\end{array}$ & $\begin{array}{c}34 \\
2 \\
1\end{array}$ & $\begin{array}{c}34(100.0) \\
0(0.0) \\
0(0.0)\end{array}$ \\
\hline $\begin{array}{l}\text { Significant and requiring } \\
\text { follow up } \\
\text { A) Atrophic Kidney } \\
\text { B) Benign Hyperplasia of } \\
\text { Prostate }\end{array}$ & $\begin{array}{l}2 \\
1\end{array}$ & $\begin{array}{l}2(100.0) \\
1(100.0)\end{array}$ \\
\hline $\begin{array}{l}\text { Insignificant } \\
\text { A) Renal Cyst (Bosnaik I \& II) } \\
\text { B) Parapelvic Cyst } \\
\text { C) Duplex collecting system } \\
\text { D) Parenchymal Scarring }\end{array}$ & $\begin{array}{c}17 \\
1 \\
2 \\
2 \\
\end{array}$ & $\begin{array}{c}14(82.4) \\
0(0.0) \\
0(0.0) \\
2(100.0)\end{array}$ \\
\hline Total & 65 & $53(81.5)$ \\
\hline
\end{tabular}

\section{Discussion}

American Urologic Association for the evaluation of adults with hematuria published the practice guidelines in 2001 and recommend initial upper urinary tract imaging with either excretory urography or CT urography, in addition to cystoscopy of the urinary bladder and urine cytology $y^{[8]}$. CT urography has much better detection rate for diagnosing urinary calculi, renal masses, renal and perirenal infections, and unsuspected extra-urinary diseases as compared to excretory urography ${ }^{[9-12]}$. CT urography has been recommended over excretory urography by the American College of Radiology in the evaluation of hematuria ${ }^{[8]}$

Many studies have discovered life threatening conditions on urinary tract imaging and so have advocated the evaluation of microscopic hematuria with upper urinary tract imaging in young adults ${ }^{[13-15]}$. Froom et al. ${ }^{[16]}$ detected malignancies only in $0.1 \%$ of subjects and concluding that asymptomatic microscopic hematuria may not require urologic investigation in patients less than 40 years. However these studies were limited as the patients were evaluated only using IVU or USG instead of CT scan. Also many of these studies only reported malignant pathologies instead of any significant finding affecting patient management.

In our study, clinically significant source of hematuria was seen in $48.9 \%$ of CT urographic examinations. The maximum numbers of cases in this group $(79.1 \%)$ were renal or ureteral calculi. Three cases of malignancy were also detected in our study. Majority of clinically significant findings (approx. 90.7\%) were evident on unenhanced images. Major conditions that were missed on unenhanced images included tiny vesical mass, renal abscess and pyonephrosis with pyelitis. Clinically insignificant findings were mostly renal cortical cysts of Bosniak category I or II and majority of them were seen on unenhanced images only $(82.4 \%)$. Majority of clinically significant findings in our study included urinary tract calculi and the detection of 
renal and vesical masses, thus justifying the superiority of CT over IVU. Also majority of these cases could be optimally evaluated with a single phase unenhanced CT without additional need for contrast enhanced and urographic images. The mean effective dose of CT urography is $14.8 \mathrm{mSv}$ which is to approximately 1.5 times the radiation risk from IVU $^{[17]}$ with doses being considerably high for split bolus protocol. So due to relatively high radiation dose in multiphase CT urography, an alternative imaging strategy in young patients with hematuria should include an unenhanced CT scan only and depending upon the presence and categorisation of clinically significant finding, contrast enhanced scan should be performed to avoid unnecessary radiation exposure to children and young adults. One of limitations of our study was small sample size as only 88 patients were included in the study.

Lokken RP et $\mathrm{al}^{[18]}$ performed a similar retrospective study to evaluate the diagnostic Yield of CT Urography in Young Adults with Hematuria. They determined the yield of CT urography for significant urologic disease to be $22.1 \%$ and concluded that a single phase unenhanced CT may be sufficient for the majority of these patients without additional predisposing medical conditions.

So we conclude that unenhanced CT alone may be significantly sufficient in evaluation of hematuria in majority of young adults, thereby reducing burden of unnecessary radiation exposure. Further, contrast enhanced scans may be reserved in patients with some significant predisposing medical conditions or where results of other investigations were suspicious or abnormal.

\section{Conflicts of Interest: Nil}

Source of Funding: Nil

Acknowledgements: Nil

\section{References}

1. Chen BTM, Ooi BS, Tan KK, Lim CH. Comparative Studies of Asymptomatic Proteinuria and Hematuria. Arch Intern Med. 1974;134(5):901-905.
2. Mohr DN, Offord KP, Owen RA, Melton LJ 3rd. Asymptomatic Microhematuria and Urologic disease. A population-based study. JAMA. 1986 Jul 11;256(2):224-9.

3. Sillettti JP, O'Leary MP. Overview of Imaging of the Urinary Tract and the Role of CT Urography. In: Silverman SG, Cohan RH, eds. CT Urography: An Atlas. $1^{\text {st }}$ Ed. Philadelphia: Lippincott Williams \& Wilkins. 2007.p.4.

4. Sanders C. Clinical urine examination and the incidence of microscopic haematuria in apparently normal males. Practitioner. 1963 Aug;191:192-7.

5. Woolhandler S, Pels RJ, Bor DH, Himmelstein DU, Lawrence RS. Dipstick urinalysis screening of asymptomatic adults for urinary tract disorders. Part I. Hematuria and proteinuria. JAMA. 1989 Sep 1;262(9):1214-9.

6. Grossfeld GD, Litwin MS, Wolf JS, Hricak $\mathrm{H}$, Shuler CL, Agerter DC, et al. Evaluation of asymptomatic microscopic hematuria in adults: the American Urological Association best practice policy. Part I. Definition, detection, prevalence, and etiology. Urology. 2001 Apr;57(4):599-603.

7. Fowler KAB, Locken JA, Duchesne JH, Williamson MR. US for detecting renal calculi with nonenhanced CT as a reference standard. Radiology. 2002 Jan;222(1):10913.

8. Grossfeld GD, Litwin MS, Wolf JS Jr, Hricak H, Shuler CL, Agerter DC et al. Evaluation of asymptomatic microscopic hematuria in adults: the American Urological Association best practice policy-part II: patient evaluation, cytology, voided markers, imaging, cystoscopy, nephrology evaluation, and follow-up. Urology. 2001 Apr;57(4):604-10.

9. Gray Sears CL, Ward JF, Sears ST, Puckett MF, Kane CJ, Amling CL. Prospective comparison of computerized tomography and excretory urography in the initial 
evaluation of asymptomatic microhematuria J Urol. 2002 Dec;168(6): 2457-60.

10. Lang EK, Thomas R, Davis R, Myers L, Sabel A, Macchia R et al. Multiphasic helical computerized tomography for the assessment of microscopic hematuria: a prospective study. J Urol. 2004 Jan;171(1):237-43.

11. Liu W, Mortele KJ, Silverman SG. Incidental extraurinary findings at MDCT urography in patients with hematuria: prevalence and impact on imaging costs. AJR Am J Roentgenol. 2005 Oct;185(4): 1051-6.

12. Albani JM, Ciaschini MW, Streem SB, Herts BR, Angermeier KW. The role of computerized tomographic urography in the initial evaluation of hematuria. J Urol. 2007 Feb;177(2):644-8.

13. Gartman E. The significance of hematuria in young men. J Urol. 1956 Jan;75(1):135-42.

14. Carson CC 3rd, Segura JW, Greene LF. Clinical importance of microhematuria JAMA. 1979 Jan 12;241(2):149-50.

15. Ritchie CD, Bevan EA, Collier SJ. Importance of occult haematuria found at screening. Br Med J (Clin Res Ed). 1986 Mar 8;292(6521):681-683.

16. Froom P, ribak J, Benbassat J. Significance of microhaematuria in young adults. Br Med J (Clin Res Ed). 1984 Jan 7;288(6410):2022.

17. Nawfel RD, Judy PF, Schleipman AR, Silverman SG. Patient radiation dose at CT urography and conventional urography. Radiology. 2004 Jul;232(1): 126-32.

17. Lokken RP, Sadow CA, Silverman SG. Diagnostic yield of CT urography in the evaluation of young adults with hematuria. AJR Am J Roentgenol. 2012 Mar;198(3):609-15. 